\section{Vietnam Journal of Agricultural Sciences}

\title{
Identification of Optimal Culture Conditions for Mycelial Growth and Cultivation of Monkey Head Mushrooms (Hericium erinaceus (Bull.: fr.) Pers)
}

\author{
Nguyen Thi Bich Thuy ${ }^{1}$, Ngo Xuan Nghien ${ }^{1}$, Le Van $\mathrm{Ve}^{2}$, \\ Nguyen Thi Luyen ${ }^{1}$, Tran Dong Anh ${ }^{1}$ and Nguyen Thi Lam Hai ${ }^{1}$ \\ ${ }^{1}$ Faculty of Biotechnology, Vietnam National University of Agriculture, Hanoi 131000 , \\ Vietnam \\ ${ }^{2}$ Department of Bioactive Material Sciences, Chonbuk National University, Jeonju \\ 54896, Republic of Korea
}

\begin{abstract}
Monkey head mushrooms (Hericium erinaceus (Bull.: Fr.) Pers) have been broadly cultivated and widely consumed as traditional medicinal herbs as well as functional food in the Orient for several hundred years of history. The identification of optimal culture conditions for mycelium growth and fruiting body formation is one of the most important steps in cultivation of mushroom. The aim of this study was to investigate the optimal culture conditions including $\mathrm{pH}$ level, temperature, media and substrate mixtures for the mycelium growth and cultivation of Hericium erinaceus strain $\mathrm{He}-2$. Results of the study revealed that the optimal conditions for mycelial growth were observed at $25 \pm 1^{\circ} \mathrm{C}$ and $\mathrm{pH}$ 8.0. $H$. erinaceus was cultured on five different types of culture media: Czapek, Raper, PGA (potato, glucose, agar), PGA supplemented with rice bran, and PGA supplemented with fresh mushrooms. PGA supplemented with fresh mushrooms was found to be the best medium for the growth of mycelia. A media containing $99 \%$ grain of rice $+1 \% \mathrm{CaCO}_{3}$ was considered as the best mother spawn media for mycelial growth. Among various culture media, the highest mycelium growth rate and biological efficiency of $H$. erinaceus were obtained when grown on a treatment of $87 \%$ sawdust $+4 \%$ corn bran $+8 \%$ rice bran $+1 \% \mathrm{CaCO}_{3}$.
\end{abstract}

\section{Keywords}

Monkey head mushroom, mycelium, media, fruiting bodies

\section{Correspondence to}

ntbthuy.cnsh@vnua.edu.vn

\section{ORCID}

Nguyen Thi Bich Thuy https://orcid.org/0000-0003-18356999

\section{Introduction}

Hericium erinaceus (Bull.: Fr.) Pers., commonly known as the monkey head mushroom, is considered as one of the best edible and medical mushrooms belonging to the family Hericiaceae, order 
Russulales, and class Agaricomycetes (Kirk et $a l ., 2008)$. It has been widely consumed as traditional medicine and functional food in Asian countries for several hundred years. $H$. erinaceus fruiting bodies and mycelia are known to produce several extensive bioactive compounds, including health promoting substances like $\gamma$-aminobutyric acid (GABA), ergothioneine, and lovastatin (Cohen et al., 2014) with different positive effects on the human body. As reported previously, various substances extracted from monkey head mushrooms have multiple pharmacological activities such as antimicrobial, anti-cancer (Gue et al., 2006), and antioxidant activities (Chyi et al., 2005), and can be used in the treatment of cancer, hepatic disorders, Alzheimer's and Parkinson's diseases, and wound healing (Sokół, 2015). In addition, $H$. erinaceus offers neuroprotective effects after ischemic brain injuries, peripheral nerve regenerative effects, and enhancement of sensory as well as functional recovery after nerve injury (Wong et al., 2012; Lee et al., 2014; Wong et al., 2015; Wong et al., 2016).

In order to obtain high quality mushroom spawn, the identification of optimal growth conditions is considered as one of the most critical steps. Therefore, the aims of this research were to evaluate various culture media, $\mathrm{pH}$, temperature and substrate mixtures for the mycelia growth and fruiting body formation of H. erinaceus.

\section{Materials and Methods}

\section{Mushroom strain}

Monkey head mushroom Hericium erinaceus strain $\mathrm{He}-2$ was obtained from the NN08 project. The culture was maintained on PGA (potato, glucose, agar) medium and stored in a refrigerator at $5-7^{\circ} \mathrm{C}$.

\section{Media preparation}

In order to prepare the culture media, potatoes were peeled, cut into small pieces, and boiled with distilled water for $30 \mathrm{~m}$. The extract was filtered using steel mesh. Glucose and agar were added to the extract and dissolved. Water was added up to $1000 \mathrm{~mL}$ and then the media was poured into bottles. The media bottles were sterilized by autoclaving them at $121^{\circ} \mathrm{C}$ for $60 \mathrm{~min}$.

Paddy grains were prepared by washing and soaking them in water for $12 \mathrm{~h}$ to moisten them. The grains were boiled with an equal volume of fresh water until the grains became soft.

Sawdust without volatile oil and poisons can be used as a main substrate for the cultivation of Hericium erinaceus. Sawdust was mixed with a lime solution (4 $\mathrm{kg}$ of lime per $1000 \mathrm{~L}$ of water). The substrates were fermented for 5-7 days and then allowed to sit an extra 1-2 days until the substrates reached a $65 \%$ moisture level. The resulting substrate was poured into bottles. Each bottle contained $300 \mathrm{~g}$ and was autoclaved at $121^{\circ} \mathrm{C}$ for $90 \mathrm{~min}$.

\section{Experiment design}

Experiment 1: Effects of different initial $\mathrm{pH}$ levels on mycelial growth

The $\mathrm{pH}$ levels of 3.0, 4.0, 5.0, 6.0, 7.0, 8.0, and 9.0 were tested for the optimum mycelia growth of $H$. erinaceus (He-2). The medium was adjusted to the different $\mathrm{pH}$ levels with the addition of $1 \mathrm{M} \mathrm{NaOH}$ or $\mathrm{HCl}$.

Experiment 2: Effects of different temperature levels on mycelial growth

The petri dishes of PGA media were inoculated with $H$. erinaceus and incubated at four temperature levels $\left(20^{\circ} \mathrm{C} \pm 1,25^{\circ} \mathrm{C} \pm 1\right.$, $30^{\circ} \mathrm{C} \pm 1$, and $35^{\circ} \mathrm{C} \pm 1$ ) under darkness conditions. Mycelial growth was recorded daily $\left(\mathrm{mm}\right.$ day $\left.^{-1}\right)$.

Experiment 3: Effects of different culture media on mycelial growth of pure spawn

The ingredients for the different culture media of pure spawn were as follows:

Treatment 1: Czapek (30 g Sucrose $+2 \mathrm{~g}$ $\mathrm{NaNO}_{3}+1 \mathrm{~g} \mathrm{KH}_{2} \mathrm{PO}_{4}+0.5 \mathrm{~g} \mathrm{MgSO}_{4} .7 \mathrm{H}_{2} \mathrm{O}+$ $0.01 \mathrm{~g} \mathrm{FeSO}_{4} .7 \mathrm{H}_{2} \mathrm{O}+0.5 \mathrm{~g} \mathrm{KCl}+20 \mathrm{~g}$ agar + $1000 \mathrm{~mL}$ distilled water)

Treatment 2: Raper $(2 \mathrm{~g}$ yeast extract $+2 \mathrm{~g}$ peptone $+0.46 \mathrm{~g} \mathrm{KH}_{2} \mathrm{PO}_{4}+1 \mathrm{~g} \mathrm{~K}_{2} \mathrm{HPO}_{4}+0.5 \mathrm{~g}$ $\mathrm{MgSO}_{4} .7 \mathrm{H}_{2} \mathrm{O}+20 \mathrm{~g}$ glucose $+20 \mathrm{~g}$ agar + $1000 \mathrm{~mL}$ distilled water) 
Treatment 3: PGA (20 g glucose $+250 \mathrm{~g}$ potatoes $+20 \mathrm{~g}$ agar $+1000 \mathrm{~mL}$ distilled water)

Treatment 4: $\mathrm{PGA}+20 \mathrm{~g}$ rice bran

Treatment 5: PGA $+25 \mathrm{~g}$ fresh oyster mushrooms.

Experiment 4: Effects of different culture media on the mycelial growth of mother spawn

The ingredients for the different culture media used to grow the mother spawn were as follows:

Treatment A: $99 \%$ rice grain $+1 \% \mathrm{CaCO}_{3}$

Treatment B: $79 \%$ rice grain $+20 \%$ sawdust $+1 \% \mathrm{CaCO}_{3}$

Treatment C: $59 \%$ rice grain $+40 \%$ sawdust $+1 \% \mathrm{CaCO}_{3}$

Treatment D: $39 \%$ rice grain $+60 \%$ sawdust $+1 \% \mathrm{CaCO}_{3}$

Treatment E: $19 \%$ rice grain $+80 \%$ sawdust $+1 \% \mathrm{CaCO}_{3}$

The substrates were transferred into glass bottles and steam-sterilized for $90 \mathrm{~min}$ at $121^{\circ} \mathrm{C}$. $H$. erinaceus was inoculated and grown on the culture media in glass bottles at $25^{\circ} \mathrm{C}$ under darkness conditions. The mycelial growth of $H$. erinaceus in the rice grain medium supplemented with sawdust was measured after several days of incubation.

Experiment 5: The growth and development of $H$. erinaceus cultivated on different substrates

For this experiment, $H$. erinaceus was cultivated on sawdust enriched by various types of supplements as follows:

Treatment I: $87 \%$ sawdust $+4 \%$ corn powder $+8 \%$ rice bran $+0 \%$ wheat bran $+1 \%$ $\mathrm{CaCO}_{3}$

Treatment II: $87 \%$ sawdust $+4 \%$ corn powder $+6 \%$ rice bran $+2 \%$ wheat bran $+1 \%$ $\mathrm{CaCO}_{3}$

Treatment III: $87 \%$ sawdust $+4 \%$ corn powder $+4 \%$ rice bran $+4 \%$ wheat bran $+1 \%$ $\mathrm{CaCO}_{3}$

Treatment IV: $87 \%$ sawdust $+4 \%$ corn powder $+2 \%$ rice bran $+6 \%$ wheat bran $+1 \%$ $\mathrm{CaCO}_{3}$
Treatment V: $87 \%$ sawdust $+4 \%$ corn powder $+0 \%$ rice bran $+8 \%$ wheat bran $+1 \%$ $\mathrm{CaCO}_{3}$

\section{Data collection}

For the culture media, temperature, and $\mathrm{pH}$ experiments, data were recorded on the following parameters: mycelial growth rate $\left(m m\right.$ day $\left.^{-1}\right)$, characteristics of the mycelia, and diameter of the mycelia.

Mycelial growth was calculated using the following formula: $\mathrm{V}=\mathrm{D} / \mathrm{T}$, where $\mathrm{V}$ is the mycelial growth rate $\left(\mathrm{mm} \mathrm{day}^{-1}\right), \mathrm{D}$ is the length of growth of the mycelia, and $\mathrm{T}$ is the duration of mycelial growth (days).

Data were also recorded on the period of surface colonization (days), the time required for mycelium to grow throughout the full media and establish total colonization on the bag surface, and the period of primordia formation (days), the time required for the formation of primordia.

Biological efficiency (BE) (\%) was calculated with the following formula:

$$
\frac{\text { Weight of mushrooms }}{\text { Weight of substrates }} \times 100
$$

\section{Statistical analysis}

The data of experiment were statistically analyzed using IRRISTAT version 5.0 and GraphPad Prism version 5.0. Each treatment was replicated three times. Differences among the means of groups were assessed using the one-way or two-way analysis of variance (ANOVA) followed by a multiple-comparison test (Bonferroni post test).

\section{Results and Discussion}

\section{Effects of pH on the mycelial growth of $\boldsymbol{H}$. erinaceus}

$\mathrm{pH}$ is generally considered to be one of the most important chemical factors that can affect cell membrane function, uptake of various nutrients, cell morphology and structure, solubility of salts, ionic state of substrates, enzyme activity, and product biosynthesis (Elisashvili, 2012). Most mushrooms grow and 
perform well at a $\mathrm{pH}$ near to neutral or slightly basic (Khan et al., 2013). According to Imtiaj et al. (2008), the $\mathrm{pH}$ values most suitable for the favorable growth of $H$. erinaceus were observed in the range of $5.0 \sim 9.0$ and the best was $\mathrm{pH} 6.0$. The other $\mathrm{pH}$ values also showed good mycelial growth, and $\mathrm{pH} 9.0$ was better than $\mathrm{pH} 5.0$ for the growth of the different strains of $H$. erinaceus. Grigansky et al. (1999) reported that for the growth of $H$. erinaceus, the optimum $\mathrm{pH}-$ level was between 5.8 and 6.2. To determine the optimum initial $\mathrm{pH}$ for mycelial growth, PGA media was inoculated with $H$. erinaceus at various initial $\mathrm{pH}$ values (3.0-9.0). The results presented in Figure 1 showed that the mycelial growth of $H$. erinaceus was affected by the initial $\mathrm{pH}$. H. erinaceus was able to grow at the $\mathrm{pH}$ range of 4.0 to 9.0 (optimally at $\mathrm{pH} 8.0$ ). Although $H$. erinaceus could grow over a wide range of $\mathrm{pH}$ values between 4.0 and 9.0, lower $\mathrm{pH}$ levels showed growth inhibition. A remarkable difference in terms of mycelial morphology was observed between acidic media ( $\mathrm{pH}$ 4.0-6.0) and alkaline media ( $\mathrm{pH} 7.0-9.0)$.

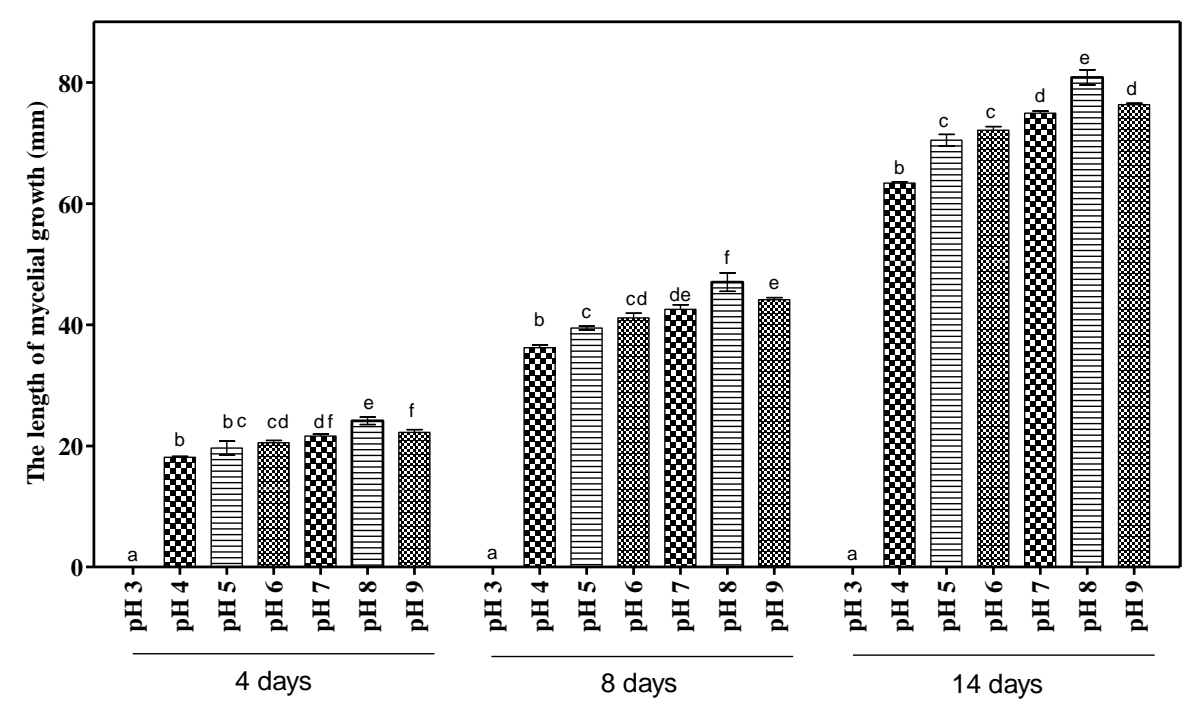

Note: $\mathrm{pH}$ 4.0, 5.0, 6.0, 7.0, 8.0, and 9.0 are values before being autoclaved. Bars in the same time period with different letters differ significantly at $P<0.05$.

Figure 1. Effects of different $\mathrm{pH}$ values on mycelial growth of $H$. erinaceus

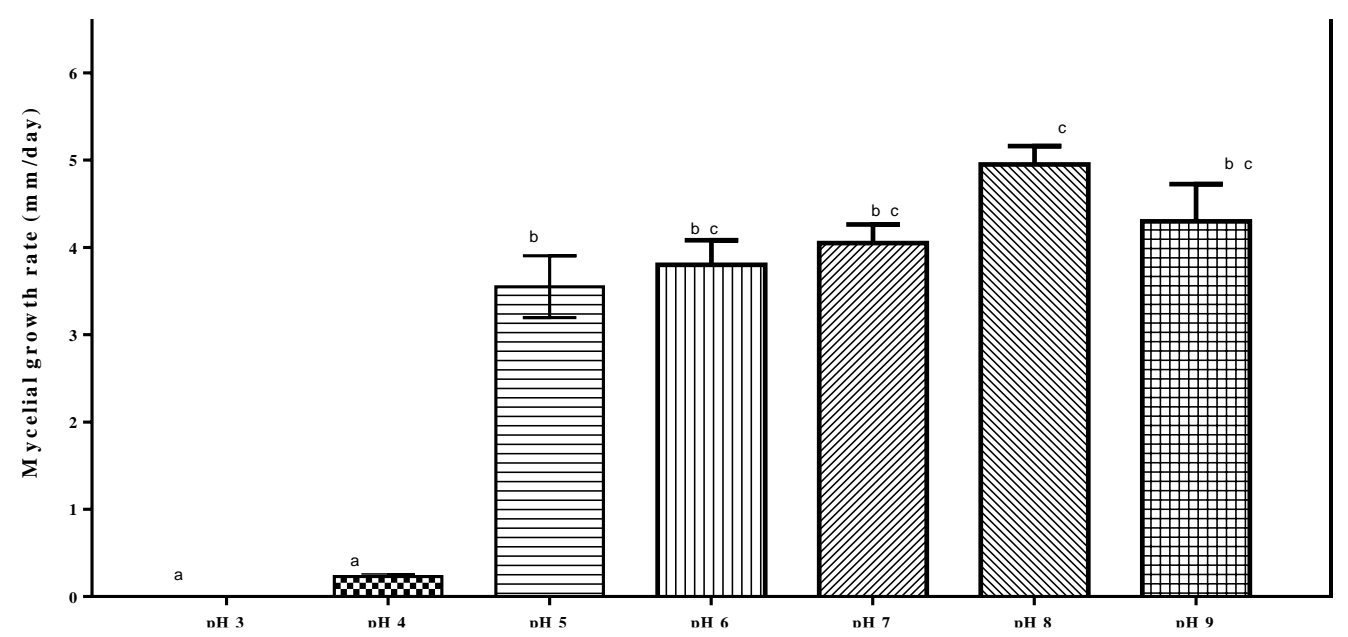

Note: Mycelial growth rate of $\mathrm{H}$. erinaceus on different $\mathrm{pH}$ levels. Bars with different letters differ significantly at $P<0.05$.

Figure 2. Effects of $\mathrm{pH}$ on the mycelial growth rate 
The mycelia of $H$. erinaceus cultivated at the initial $\mathrm{pH}$ values of 4.0, 5.0, and 6.0 had a white color for the first 8 days, but changed to brown at the center of the plate after 20 days of incubation. In contrast, mycelia had a lighter white color for the first 10 days and remained white after 30 days of incubation in the alkaline media. The fastest spawn running time of the mycelia in pure culture was observed at $\mathrm{pH} 8.0$ level. Therefore, we recommend this $\mathrm{pH}$ for the best mycelial growth of $H$. erinaceus in PGA media.

\section{Effects of temperature on the mycelial growth of $\mathrm{H}$. erinaceus}

Like $\mathrm{pH}$ and other external factors, temperature is a significant physical factor that affects the growth of mycelium as well as fruiting body formation. Enzymatic activity and vitamin synthesis of fungi are also affected by temperature (Miles and Chang, 1997; Colauto et al., 2008). For assaying the effect of temperature, mycelial growth of $H$. erinaceus was recorded at four different temperature levels, including $20^{\circ} \mathrm{C} \pm 1,25^{\circ} \mathrm{C} \pm 1,30^{\circ} \mathrm{C} \pm 1$, and $35^{\circ} \mathrm{C} \pm 1$. The average values of three replications in each treatment were calculated and used as quantitative measures for comparing growth. According to Ahmed et al. (2008), the incubation temperature most suitable for the mycelial growth of $H$. erinaceusis was found to be $25^{\circ} \mathrm{C}$. The optimum temperature for vegetative growth was observed to be $26^{\circ} \mathrm{C}$ (Grigansky et al., 1999).

For this experiment, we used PGA as the medium for inoculating the $H$. erinaceus strain He-2. The results of the observations are shown in Figure 3 and Table 1. The results indicated that $H$. erinaceus can grow at all the temperatures tested between $20-35^{\circ} \mathrm{C}$. However, the maximum growth was achieved with the temperature $25^{\circ} \mathrm{C} \pm 1$ $(85.84 \mathrm{~mm})$ followed by $30^{\circ} \mathrm{C} \pm 1(80.20 \mathrm{~mm})$, and $20^{\circ} \mathrm{C} \pm 1(75.26 \mathrm{~mm})$ after 14 days of incubation. Therefore, these results suggest that the best temperature for maximum mycelial growth of $H$. erinaceus is $25 \pm 1^{\circ} \mathrm{C}$. Under this condition, the density of the mycelia was thick with a white color and corroborates with the results of Ahmed et al. (2008).

Effects of different culture media on the mycelial growth of pure spawn

There are many types of culture media with

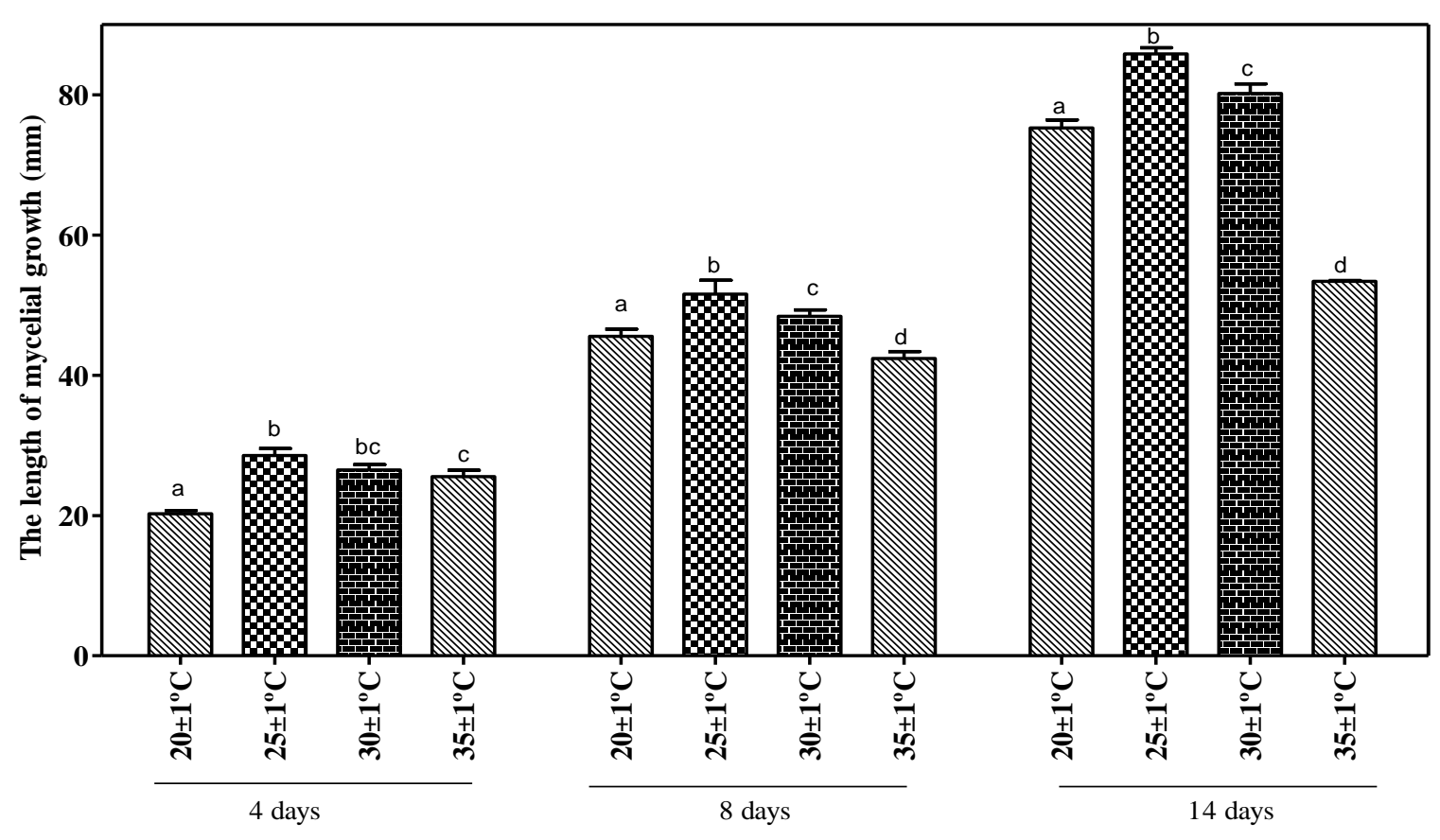

Note: Bars in the same time period with different letters differ significantly at $P<0.05$.

Figure 3. The mycelial growth of $H$. erinaceus on different temperature levels 
Table 1. Effects of different temperature levels on mycelial growth of $H$. erinaceus

\begin{tabular}{|c|c|c|c|}
\hline Temp. level Factors & $\begin{array}{l}\text { Mycelium run rate } \\
\left.\left(\mathrm{mm}_{\text {day }}\right)^{-1}\right)\end{array}$ & $\begin{array}{l}\text { Mycelial } \\
\text { density }\end{array}$ & Mycelial characteristics \\
\hline $20 \pm 1^{\circ} \mathrm{C}$ & 3.16 & ++ & $\begin{array}{l}\text { Mycelia density was thick with a light white color. Media were } \\
\text { colonized incompletely. Fruiting body formation occurred. }\end{array}$ \\
\hline $25^{\circ} \mathrm{C} \pm 1$ & 4.78 & +++ & $\begin{array}{l}\text { Mycelial density was thick with a white color. Media were } \\
\text { colonized completely. }\end{array}$ \\
\hline $30^{\circ} \mathrm{C} \pm 1$ & 4.30 & ++ & $\begin{array}{l}\text { Mycelia density was thin with a light white color. Media were } \\
\text { colonized completely. }\end{array}$ \\
\hline $35^{\circ} \mathrm{C} \pm 1$ & 2.82 & + & Mycelia density was very thin. Media were colonized incompletely. \\
\hline CV\% & 1.00 & & \\
\hline $\operatorname{LSD}_{(0.05)}$ & 0.16 & & \\
\hline
\end{tabular}

different nutrient compositions that can be used for the vegetative growth of mushrooms. In this experiment, five different culture media were screened to determine the optimal media for mycelial growth of $H$. erinaceus. As shownin Table $2, H$. erinaceus was able to grow on all five types of media tested. However, comparatively, the most suitable medium for mycelial growth was PGA supplemented with fresh mushroom extracts, corresponding to the mycelial growth rate of $3.73 \mathrm{~mm}_{\text {day }}{ }^{-1}$. In addition, in terms of mycelial characteristics, the color of the mycelium was white in three type of media (PGA supplemented with fresh oyster mushrooms, PGA supplemented with rice bran, and Raper media).

\section{Effects of different culture media on the mycelial growth of mother spawn}

Following the results of the pure spawn media experiment, pure cultured spawn was inoculated into new medium to produce mother spawn. Cereal, rice bran, and sawdust are considered as the basic ingredients of culture media for the growth of mother spawn. For this study, we selected paddy rice and sawdust supplemented with $\mathrm{CaCO}_{3}$ as the main components of the experiment treatment. Treatment $\mathrm{B}$ and $\mathrm{C}$ were the common culture media used for mushroom cultivation with a ratio of $79 \%$ rice grain $+20 \%$ sawdust $+1 \%$ $\mathrm{CaCO}_{3}$, and $59 \%$ rice grain $+40 \%$ sawdust + $1 \% \mathrm{CaCO}_{3}$, respectively, and showed the best mycelial growth. The mycelium extension rate was fast with a poor density in treatment 5. By contrast, because rice grain media was rich in nutrition, allowed for mycelium respiration, and allowed the mycelium to easily grow into the substrate, the mycelium run rate was fast with a high density in treatment 1 . These results suggest that rice grain should be used as a nutrient source in the culture medium for the development of mother spawn.

\section{Effects of different substrates on fruiting body formation and biological efficiency of H. erinaceus}

Sawdust was selected as the most preference basal ingredient in the substrate mixtures for $H$. erinaceus cultivation. In order to determine the best combination, correlation analyses were carried out. Sawdust, however, is well known as a substrate poor in nutrients. Therefore, to reduce the cultivation time and promote economic efficiency, the cultivation media was supplemented with essential nutrients for mycelial growth. In this experiment, we used corn bran, rice bran, and wheat bran in different percentages to determine the best formula for the growth and development of the mycelium.

$\mathrm{BE}$ is an important factor in mushroom cultivation and is the major purpose of this set of experiments. Sawdust was tested with three kinds of brans as supplements. Treatment I and treatment II had rice bran and corn bran which are high in vitamins and suitable for fruiting body development stage. As such, the highest 
Table 2. Effects of different culture media on the mycelial growth of $H$. erinaceus pure spawn

\begin{tabular}{|c|c|c|c|}
\hline Media Factors & $\begin{array}{l}\text { Mycelium run rate } \\
\left(\mathrm{mm} \text { day }^{-1}\right)\end{array}$ & Mycelial density & Mycelial characteristics \\
\hline Czapek & 2.58 & + & $\begin{array}{l}\text { Mycelia density was very thin with a white color. } \\
\text { Media were colonized incompletely. }\end{array}$ \\
\hline Raper & 3.42 & ++ & $\begin{array}{l}\text { Mycelia density was thick with a white color and } \\
\text { colonized incompletely. Fruiting body formation did } \\
\text { not occur. }\end{array}$ \\
\hline PGA & 3.38 & ++ & $\begin{array}{l}\text { Mycelia density was thick with a white color. Media } \\
\text { were not colonized completely and stopped growing } \\
\text { after } 22 \text { days of incubation. }\end{array}$ \\
\hline $\begin{array}{l}\text { PGA supplemented with } \\
\text { rice bran }\end{array}$ & 3.56 & +++ & $\begin{array}{l}\text { Mycelia density was thick with a white color. Media } \\
\text { were fully colonized after } 24 \text { days of incubation. } \\
\text { Fruiting body formation did not occurred. }\end{array}$ \\
\hline $\begin{array}{l}\text { PGA supplemented with } \\
\text { fresh mushrooms }\end{array}$ & 3.73 & +++ & $\begin{array}{l}\text { Mycelia density was thick with white color. Media } \\
\text { were fully colonized after } 21 \text { days of incubation. }\end{array}$ \\
\hline CV\% & 1.12 & & \\
\hline $\mathrm{LSD}_{0.05}$ & 0.65 & & \\
\hline
\end{tabular}

Note: +++: High; ++: Regular; +: Low.

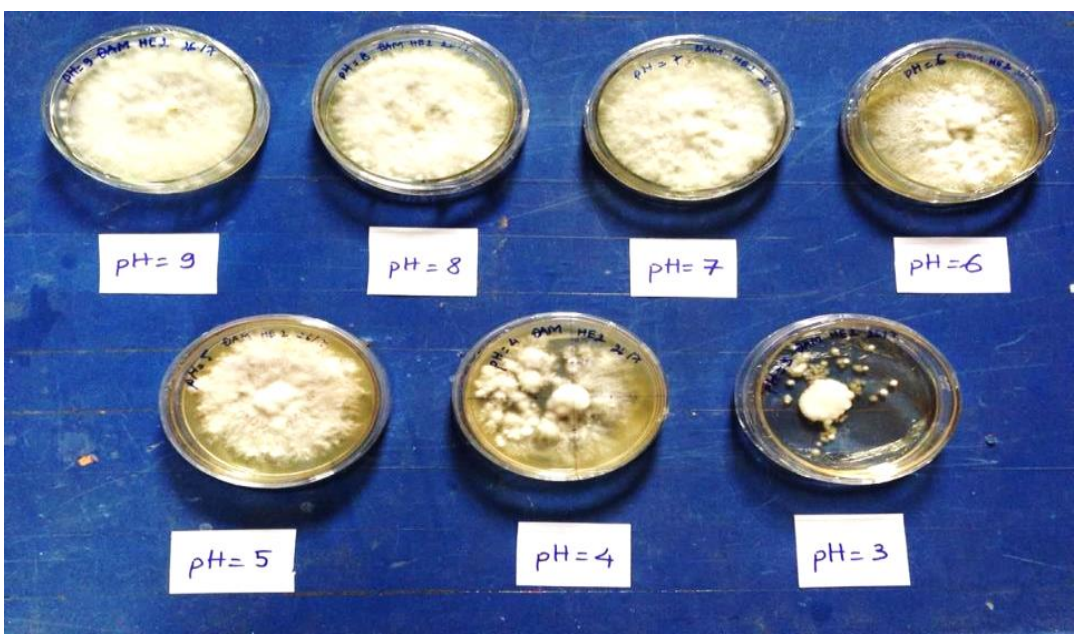

Figure 4. Mycelial growth on plates with different $\mathrm{pH}$ levels 20 days after inoculation

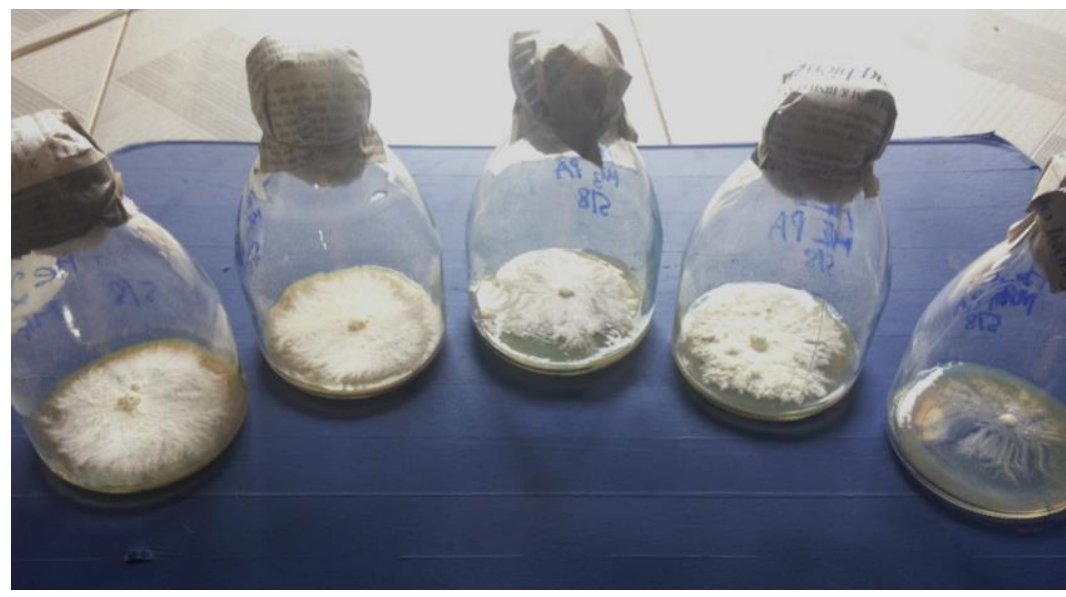

Figure 5. Mycelial growth on different media 20 days after inoculation (right-to-left: media 1 to 5) 


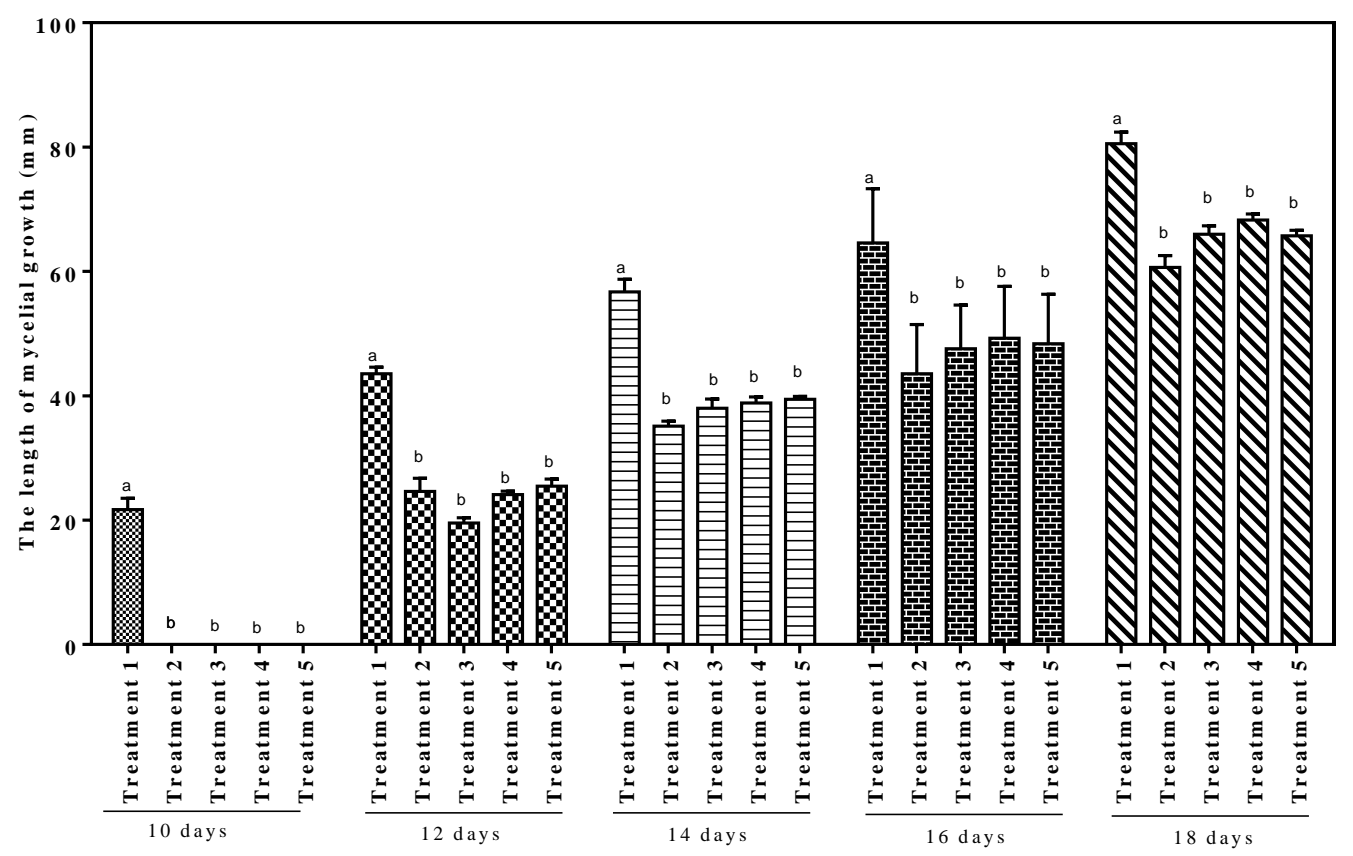

Note: Bars in the same time period with different letters differ significantly at $P<0.05$.

Figure 6. Effects of different grade 1 culture media on the mycelial growth of $H$. erinaceus

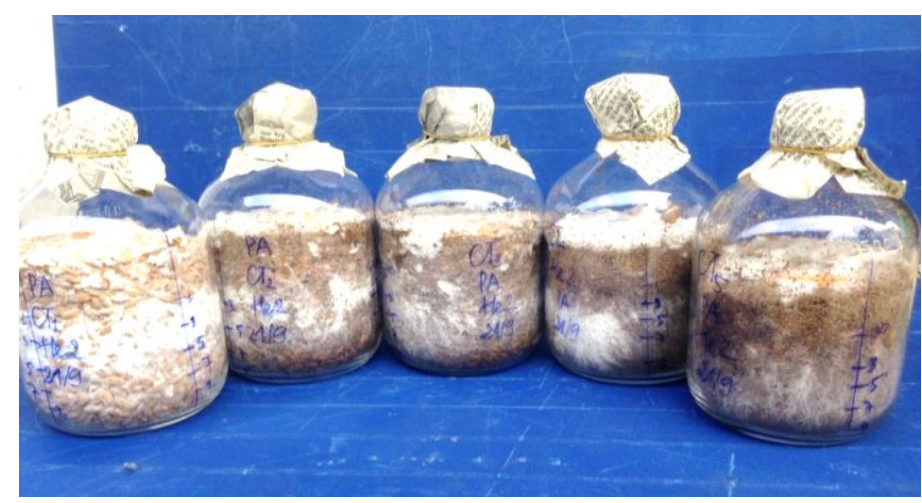

Figure 7. Mycelial growth on different substrates 20 days after inoculation

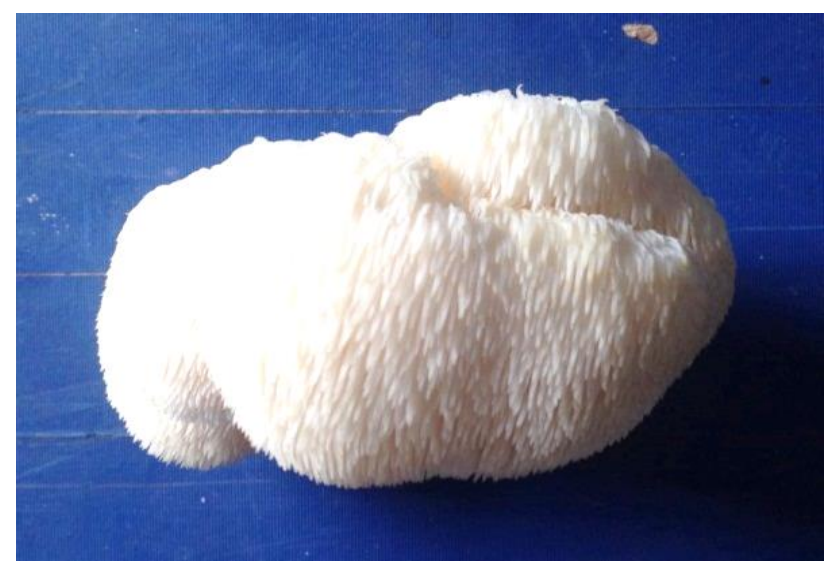

Figure 8. Fruiting body of $H$. erinaceus cultivated on formula 


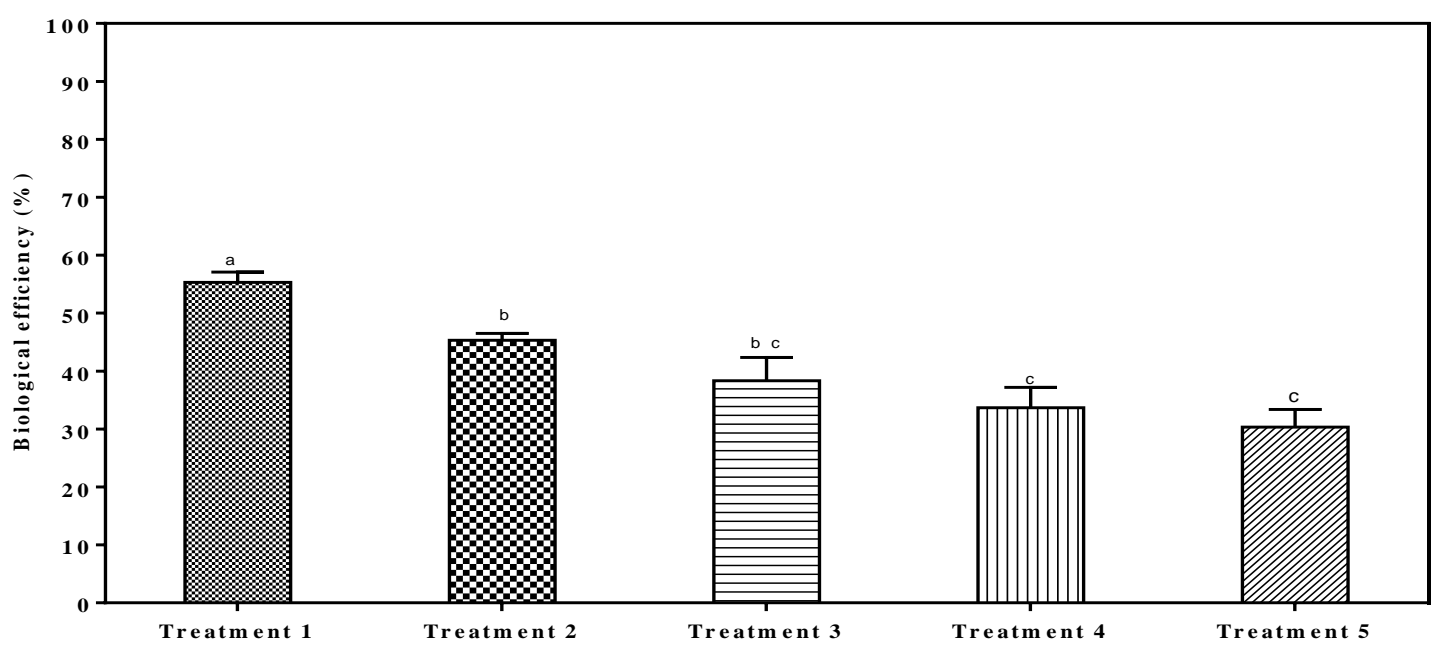

Note: Bars with different letters differ significantly at $P<0.05$.

Figure 9. Biological efficiencies of $H$. erinaceus grown on different substrates

$\mathrm{BE}$ value of $56.54 \%$ was obtained using treatment 1 , and was followed by treatment 2 (45.44\%). Treatments 4 and 5 had low BE values $(33.02 \%$ and $30.56 \%$, respectively) due to the lower percentage of rice bran than treatment 1 and 2 . For treatment 3 , the period of primordia formation required the longest time, and the biological efficiency had a higher value than treatments 4 and 5. The findings of the present study are in agreement with those obtained by Gyu et al. (2005) and Swiulski and Sobieralski (2005).

\section{Conclusions}

The $\mathrm{pH}$ value of 8.0 was determined to be the optimum $\mathrm{pH}$ for mycelial growth of $H$. erinaceus with a maximum growth diameter of $81.0 \mathrm{~mm}$ after 14 days of incubation. The ideal temperature for mycelial growth was determined to be $25^{\circ} \mathrm{C}$. PGA enriched with fresh oyster mushrooms was the most suitable for mycelial growth of $H$. erinaceus, which showed a maximum growth of $3.73 \mathrm{~mm} \mathrm{day}^{-1}$. The treatment of $99 \%$ rice grain + $1 \% \mathrm{CaCO}_{3}$ was selected as the most favorable mother spawn media for the fastest mycelial growth rate and high mycelial density. With the biological productivity of $56.54 \%$, the treatment containing $87 \%$ sawdust $+4 \%$ corn powder $+8 \%$ rice bran $+1 \% \mathrm{CaCO}_{3}$ was considered to be the most suitable substrate to cultivate $H$. erinaceus.

\section{Acknowledgements}

We thank the NN08 project for providing H. erinaceus strain $\mathrm{He}-2$.

\section{References}

Chyi W. J., Hui H. S., Teng W. J., Shao C. K. and Chen C. Y. (2005). Hypoglycemic effect of extract of Hericiumerinaceus. Journal of the Science of Food and Agriculture. Vol 85 (4). pp. 641-646.

Cohen N., Cohen J., Asatiani M. D., Varshney V. K., Yu H. T. and Yang Y. C. (2014). Chemical composition and nutritional and medicinal value of fruit bodies and submerged cultured mycelia of culinarymedicinal higher Basidiomycetes mushrooms. International Journal of Medicinal Mushrooms. Vol 16. pp. 273-291.

Colauto N. B., Aizono P. M., Carvalho L. R. M., PaccolaMeirelles L. D. and Linde G. A, (2008). Temperature and $\mathrm{pH}$ conditions for mycelial growth of Agaricus brasiliensis on axenic cultivation. Semina: Ciencias Agrarias. Vol 29 (2). pp. 307-312.

Elisashvili V. (2012). Submerged cultivation of medicinal mushrooms: bioprocesses and products (Review). International Journal of Medicinal Mushrooms. Vol 14. pp. 211-239.

Grigansky A. Ph., Solomko E. F. and Kirchhoff B. (1999). Mycelial Growth of Medicinal Mushroom Hericium erinaceus (Bull.: Fr.) Pers. in Pure Culture international Journal of Medicinal Mushrooms. Vol 1 (1). pp. 81-87.

Gue S. C., Woo S. J, Hyo C. J., Kwan C. C, Heui Y. C., Tae C. W. and Hyun H. S. (2006). Macrophage 
activation and nitric oxide production by water soluble component of Hericiumerinaceum. International Immunopharmacology. Vol 6 (8). pp. 1363-1369.

Gyu K. H., Gu P. H., Ho P. S., Won C. C., Hwan K. S. and Mok P. W. (2005). Comparative study of mycelial growth and basidomata formation in seven different species of the edible mushroom genus Hericium. Bioresource-Technology. Vol 96 (13). pp. 1439-1444.

Imtiaj A., Jayasinghe C., Lee G. W, Shim M. J., Rho H. S., Lee H. S., Hur H., Lee M. W., Lee U. Y. and Lee T. S. (2008). Vegetative Growth of Four Strains of Hericiumerinaceus collected from different habitats. Mycobiology. Vol 36 (2). pp. 88-92.

Khan M. W., Ali M. A., Khan N. A., Khan M. A., Rehman A and Javed N. (2013). Effect of different levels of lime and $\mathrm{pH}$ on mycelial growth and production efficiency of oyster mushroom (PLEUROTUS spp.). Pakistan Journal of Botany. Vol 45 (1). pp. 297-302.

Kirk P. M., Cannon P. F., Minter D. W. and Stalpers J. A. (2008). Dictionary of the fungi. $10^{\text {th }}$ ed. Wallingford: CAB International. pp. 313.

Lee K. F., Chen J. H., Teng C. C., Shen C. H., Hsieh M. C., Lu C. C., Lee K. C., Lee L. Y., Chen W. P., Chen C. C., Huang W. S. and Kuo H. C. (2014). Protective effects of Hericiumerinaceus mycelium and its isolated erinacine A against Ischemia-Injury-Induced Neuronal Cell Death via the Inhibition of iNOS/p38 MAPK and Nitrotyrosine. International Journal of
Molecular Sciences. Vol 15. pp. 15073-15089.

Miles P. G. and Chang S. T. (1997). Mushroom biology: concise basics and current developments. Singapore: World Scientific Press. pp. 1-9.

Siwulski M. and Sobieralski K. (2005). Influence of some growing substrate additives on the Hericiumerinaceum (Bull., Fr.) pers. yield. Sodinikyste Darzininkyste. Vol 24 (3). pp. 2250-2253.

Sokół S., Golak-Siwulska I., Sobieralski K., Siwulski M. and Górka K. (2015). Biology, cultivation, and medicinal functions of the mushroom Hericiumerinaceum. Acta Mycologica. Vol 50 (2). pp. 1069.

Wong K. H., Kanagasabapathy G., Bakar R., Phan C. W. and Sabaratnam V. (2015). Restoration of sensory dysfunction following peripheral nerve injury by the polysaccharide from culinary and medicinal mushroom, Hericium erinaceus (Bull.: Fr.) Pers. through its neuroregenerative action.Food Science and Technology (Campinas). Vol 35 (4). pp. 712-721.

Wong K. H., Kanagasabapathy G., Naidu M., David P. and Sabaratnam V. (2016). Hericium Erinaceus (Bull.: Fr.) Pers., A Medicinal Mushroom, Activates Peripheral Nerve Regeneration. Chinese Journal of Intergrative Medicine. Vol 22 (10). pp. 759-767.

Wong K. H., Naidu M., David R. P., Bakar R. and Sabaratnam V. (2012). Neuroregenerative potential of lion's mane mushroom, Hericium erinaceus (Bull.: Fr.) Pers. (higher basidiomycetes), in the treatment of peripheral nerve injury. International Journal of Medicinal Mushrooms. Vol 14 (5). pp. 427-446. 